\title{
Mechanisms of Fever Induced by Recombinant Human Interferon
}

\author{
Charles A. Dinarello, Harry A. Bernheim, Gordon W. Duff, \\ Hung V. Le, T. L. Nagabhushan, \\ Nancy C. Hamilton, and Flavio Coceani \\ Department of Medicine, Division of Experimental Medicine, \\ Tufts University School of Medicine, Boston, Massachusetts \\ 02111; Department of Biology, Tufts University, Medford, \\ Massachusetts 02155; Department of Medicine, Yale University \\ School of Medicine, New Haven, Connecticut 06510; Schering \\ Corp., Kenilworth, New Jersey 07033; Research Institute, \\ The Hospital for Sick Children, Toronto, Ontario, Canada
}

bstract. Since the early trials using human interferon (hIFN) derived from blood leukocytes or cell lines, fever has been a prominent component of IFN therapy. Human protein impurities might account for the fever to cell-derived hIFN, but recombinant hIFN, free of extraneous human proteins, has produced fever in nearly all recipients during clinical trials. Our present studies were carried out to determine the mechanisms of fever due to recombinant hIFN currently being used in humans. Because recombinant hIFN is produced in Escherichia coli, in these experiments we considered contaminating endotoxin as the cause of fever. Polymyxin B, which blocks endotoxin, had no effect on the pyrogenicity of hIFN in rabbits. In addition, hIFN injected into an endotoxin-resistant strain of mice produced fever. The pyrogenicity of hIFN does not appear to involve production of leukocytic pyrogen (LP), since no circulating LP was detected in rabbits during IFN fever. Furthermore, human mononuclear cells incubated with hIFN in vitro at $10^{4}-10^{6} \mathrm{U} / \mathrm{ml}$ did not release LP. However, hIFN stimulated prostaglandin $\mathrm{E}_{2}\left(\mathrm{PGE}_{2}\right)$ release from rabbit hypothalamic tissue in vitro. Intracerebroventricular injection of hIFN into the awake cat also produced fever and a rise in $\mathrm{PGE}_{2}$ levels in the cerebrospinal fluid; both effects were reversed by treatment with indomethacin. We conclude that the fever of recombinant hIFN is not due to endotoxin but that

Received for publication 17 November 1983 and in revised form 30 April 1984.

J. Clin. Invest.

(c) The American Society for Clinical Investigation, Inc. 0021-9738/84/09/0906/08 \$1.00

Volume 74, September 1984, 906-913
hIFN is intrinsically pyrogenic by inducing $\mathrm{PGE}_{2}$ in the hypothalamus.

\section{Introduction}

From the first trials using semi-purified interferon (IFN) ${ }^{1}$ that was derived from virus-infected human leukocytes (hIFN), fever has been the most consistent side effect of IFN therapy (1-3). Considerable interest has centered on the pyrogenicity of IFN (4) but, as different IFNs with increasing levels of purity became available for clinical trials, fever was still observed $(5,6)$. The febrile response to IFNs vary with the dose, type, and route of administration. The fever is characterized by a prodromal shaking chill that leads to an elevation of body temperature, which reaches maximal values after 4-8 h. Unlike leukocyte-derived IFN (IFN-alpha), fibroblast-derived IFN (IFN-beta) rarely causes fever after intramuscular injection. By the intramuscular route, however, IFN-beta does not reach detectable blood levels, whereas intravenous injection of IFNalpha and IFN-beta produces the same side effects as above (7). There is also a well-described thermal ceiling, in that fever does not exceed certain levels, regardless of the dose of IFN used. In addition, pyrogenic tolerance often develops with daily administration.

Four factors could account for the fever induced by human cell-derived IFNs: $(a)$ contamination of the preparations with gram-negative bacterial lipopolysaccharide (endotoxin); (b) contamination with leukocytic pyrogen (LP), which is likely formed in leukocytes during virus induction of IFN; $(c)$ the presence of an intrinsic pyrogenic structure in the IFN molecule; and/or $(d)$ induction of LP from monocytes or macrophages

1. Abbreviations used in this paper: ET, endotoxin; hIFN, human IFN; IFN, interferon; LP, leukocytic pyrogen; LAL, Limulus amebocyte lysate test; MEM, minimal essential medium; MNC, mononuclear cells; $P$, prostaglandin; $\mathrm{PGE}_{2}$, prostaglandin $\mathrm{E}_{2} ; \mathrm{RPD}$, rabbit pyrogen dose. 
in vivo. Available evidence suggests that endotoxin is an unlikely contaminant since both the Limulus amebocyte lysate (LAL) test and the U. S. Pharmacopeia (USP) standard rabbit pyrogen test usually do not detect significant endotoxin concentrations in preparations of IFN that are highly pyrogenic for humans. The second possibility is also unlikely since IFN produced from either fibroblasts or lymphoblastoid cell lines is pyrogenic even though these cell lines do not produce LP. Lastly, IFN may have pyrogenic properties, since the fever correlates best with antiviral biological potency rather than either the cell source or the level of purification (1-7). If IFN is intrinsically pyrogenic, its action could still be mediated by the release of LP which, in turn, is responsible for the fever. This latter possibility has not been carefully investigated.

The availability of hIFN that is produced by recombinant strains of Escherichia coli has provided investigators with more than adequate supplies of highly purified compound. However, this technology brings with it the formidable problem of endotoxin contamination since the IFN must be extracted from large quantities (kilogram) of bacterial concentrates. The recent use of hIFN that is derived from recombinant strains of $E$. coli in human trials $(8,9)$ has once again focused on the pyrogenic effect of this molecule. The aim of the present study was to determine the basis of the pyrogenicity of recombinant hIFN by paying close attention to possible endotoxin contamination as well as other mechanisms for the febrile response to this biological modifier.

\section{Methods}

Materials. All glassware and containers were pyrogen-free. Various media were tested in the LAL test by using lysate (Associates of Cape Cod, Woods Hole, MA), which had a sensitivity of $0.025 \mathrm{ng} / \mathrm{ml}$. Eagle's minimal essential medium (MEM) was obtained from Microbiological Associates (Walkerville, MD) and polymyxin B from Pfizer, Inc. (New York). Indomethacin (Sigma Chemical Co., St. Louis, MO) was dissolved in ethanol $(10 \mathrm{mg} / \mathrm{ml})$ and was diluted in phosphate buffer for in vivo studies. Human recombinant leukocyte interferon (hIFN-alpha ${ }_{2}$ ) was provided by Schering Corp. The preparations consisted of $1-\mathrm{mg}$ lyophilized aliquots that contained $10^{8}$ antiviral $\mathrm{U} / \mathrm{mg}$. The LAL test was performed at Schering Corp. and at Tufts University and revealed 7.5-12.5 ng endotoxin/mg. The USP rabbit pyrogen test carried out by Schering before lyophilization at $5 \times 10^{6} \mathrm{U} / \mathrm{kg}$ yielded $1.8^{\circ} \mathrm{C}$ total fever in three rabbits (sum of maximal fever in three rabbits). The diluent for hIFN was MEM, water, or Elliott's solution artificial cerebrospinal fluid (CSF) (Abbott Laboratories, Montreal), respectively for in vitro experiments, systemic injections, and intracerebroventricular injections. Vials containing the IFN vehicle or IFN without vehicle were provided by Schering Corp. Highly purified human LP was used in the hypothalamic incubations; details concerning purification and assay have been described previously (10). LP for these experiments was purified by specific immunoaffinity chromatography; and gel-filtration. Sodium dodecyl sulfate (SDS)-gel electrophoresis revealed a single band when stained with Coomassie Blue. The assay of pyrogenic activity in LP standards was made by using the rabbit pyrogen dose (RPD), which is the amount of LP necessary to produce a peak rise in rectal temperature between 0.6 and $0.9^{\circ} \mathrm{C}$ in 2.2-kg rabbits (11). Endotoxin was national reference endotoxin RE-2 $E$. coli, kindly provided by the Bureau of Biologics (Bethesda, MD).

Rabbit pyrogen assay. New Zealand-derived albino female rabbits that weighed $\sim 2.2 \mathrm{~kg}$ were obtained from a single supplier. They were housed and trained for pyrogen testing as previously described (12). Core temperatures were measured by using indwelling rectal Yellow Springs thermistors (Yellow Springs Instrument Co., Yellow Springs, $\mathrm{OH}$ ) and recorded every minute on a Digistrip II (Kaye Instruments, Bedford, MA). Because human products were contained in materials for pyrogen testing, rabbits were not used after five consecutive days of testing to avoid the development of hypersensitivity to human antigens. Fever was measured by the peak rise above base-line recordings.

Mouse pyrogen assay. Details concerning the mouse pyrogen assay have been described recently (13). Briefly, mice were injected in the tail vein and their rectal temperatures were recorded manually every 10-15 min (Yellow Springs Instrument Co.). The $\mathrm{C} 3 \mathrm{H} / \mathrm{HeJ}$ (females) strain of endotoxin-resistant mice were acquired from a breeding colony at Yale University. For the present study these mice were unresponsive to $7.5 \mathrm{ng} E$. coli endotoxin i.v. The mean ( $\pm \mathrm{SEM})$ changes in rectal temperatures from time 0 were calculated for three to four mice.

Cat intracerebroventricular injection. Cats of either sex (weighing $\sim 3 \mathbf{~ k g}$ ) were fitted with a guide cannula inside the third ventricle. The procedures for cannulation, intraventricular injections, and collections of CSF followed a published protocol (14). Experiments were conducted in conscious animals in which colonic and ear temperatures were continuously monitored. hIFN was injected intraventricularly (third ventricle) at a dose of 0.5 or $1.25 \times 10^{6} \mathrm{U}$ (using an injectate volume of either $10-25$ or $125 \mu \mathrm{l}$, respectively), which produced a temperature elevation $>1{ }^{\circ} \mathrm{C}$. In certain cases, a larger amount of hIFN $\left(2.5 \times 10^{6}\right.$ $\mathrm{U}$ in $50 \mu \mathrm{l})$ was used. CSF $(120-280 \mu \mathrm{l})$ was collected at intervals of 0.5 and $3 \mathrm{~h}$, depending on the pattern of responses to hIFN. Control injections consisted of appropriate volumes of hIFN vehicle in Elliott's solution and Elliott's solution alone. At the end of the experimental series, the location of the intraventricular cannula was confirmed as previously described (14).

Human mononuclear cell (MNC) incubations. The MNC layer was obtained after separation on Ficoll-Hypaque gradients (15). Cells were suspended at $5 \times 10^{6}$ cells $/ \mathrm{ml}$ in MEM that contained $0.01 \mathrm{M}$ Hepes buffer, penicillin $\mathrm{G}(100 \mathrm{U} / \mathrm{ml})$, and streptomycin $(100 \mu / \mathrm{ml})$, in $5-\mathrm{ml}$ aliquots in $25-\mathrm{cm}^{2}$ flat-bottomed flasks (Corning Plastics, Corning, NY). hIFN was freshly reconstituted in MEM and added to the cells. Positive control incubations were carried out by using a suspension of boiled Staphylococcus albus, as previously described (16). MNC were incubated at $37^{\circ} \mathrm{C}$ in $5 \% \mathrm{CO}_{2}$ for $24 \mathrm{~h}$. After incubation, the supernatant was separated by centrifugation at $1,500 \mathrm{~g}$ and kept at $4^{\circ} \mathrm{C}$ until assayed in rabbits. The assay of human LP in MNC supernatants has been described elsewhere (11). Each supernatant was assayed in three rabbits by using the equivalent volume derived from $1 \times 10^{6}$ monocytes $/ \mathrm{kg}$.

Rabbit hypothalamic incubations. Rabbits were killed by rapid asphyxiation with $\mathrm{CO}_{2}$. The anterior hypothalamus was quickly removed and placed in ice-cold MEM as previously described (17). The tissue was weighed, minced into $0.5-\mathrm{mm}^{3}$ sections, and suspended in MEM at a concentration of $10 \mathrm{mg} / \mathrm{ml}$. Aliquots of the suspension $(1 \mathrm{ml})$ were then placed in $12 \times 75$-mm polypropylene tubes (Falcon Plastics, Oxnard, CA), incubated in a shaking water-bath at $37^{\circ} \mathrm{C}$ for $30 \mathrm{~min}$, diluted with $3 \mathrm{ml} 37^{\circ} \mathrm{C}$ MEM, and centrifuged at $100 \mathrm{~g}$ for $5 \mathrm{~min}$. The supernatant fluid was discarded and $1 \mathrm{ml}$ of fresh MEM containing the appropriate dilution of various compounds was added to duplicate 
tubes. Suspensions were incubated again in the shaking water-bath for $60 \mathrm{~min}$. Supernatants were collected after centrifugation at $100 \mathrm{~g}$, immediately frozen in dry ice, and stored at $-70^{\circ} \mathrm{C}$ until assayed. Supernatants from each tube were assayed in duplicate for prostaglandin $\mathrm{E}_{2}\left(\mathrm{PGE}_{2}\right)$, which yielded four data points for each experimental incubation additive.

Radioimmunoassays. $\mathrm{PGE}_{2}$ was assayed directly in CSF samples by using a specific antibody (Pasteur Institute, Paris) as outlined in previous publications $(14,18)$. A radioimmunoassay kit (Seragen, Boston, MA) using a specific anti-PGE 2 antibody was used for assays of hypothalamic incubations. Because of low protein content, these samples were not extracted before assay. Data are expressed as the mean \pm SEM. Statistical comparison of the means were made using an unpaired $t$ test.

\section{Results}

Pyrogenicity of recombinant hIFN in rabbits. Initial studies were carried out to determine the dose-response for hIFN in the rabbit pyrogen assay. After intravenous injection, minimal pyrogenic responses were observed at $10^{5} \mathrm{U} / \mathrm{kg}$, whereas 5 $\times 10^{6} \mathrm{U} / \mathrm{kg}$ produced a moderate peak fever of $\sim 0.7^{\circ} \mathrm{C}$ (Fig. 1). The febrile pattern in individual rabbits given the latter dose is illustrated in Fig. 2. The fever is monophasic and reaches maximal elevation between 75 and $110 \mathrm{~min}$ after bolus injection. The mean fever peak in the 15 rabbit injections shown in Fig. 2 occurred at $86 \pm 8 \mathrm{~min}$. In another experiment, rabbits were given an intramuscular injection of IFN into the hind leg and fevers of equal magnitude were observed with peak elevation after 150-180 min (data not shown). In contrast, the mean fever peak after intravenous bolus injection of human LP was $47 \pm 9$ min (calculated from 100 individual rabbit injections where the peak fever reached $0.4-0.9^{\circ} \mathrm{C}$ ). Like LP fever, there is no major second peak to hIFN as is often observed with endotoxin and other exogenous pyrogens (12).

To test for the development of pyrogenic tolerance to hIFN $(12,19,20)$, rabbits were injected on three successive days. As

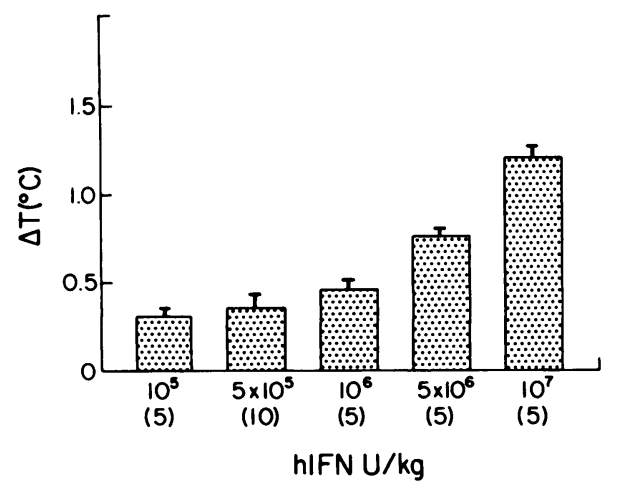

Figure 1. Dose response of rabbits to intravenous injection of hIFN Peak fever (mean \pm SEM) above base line is indicated on the vertical axis. Number of rabbits in each group is given in parenthesis.

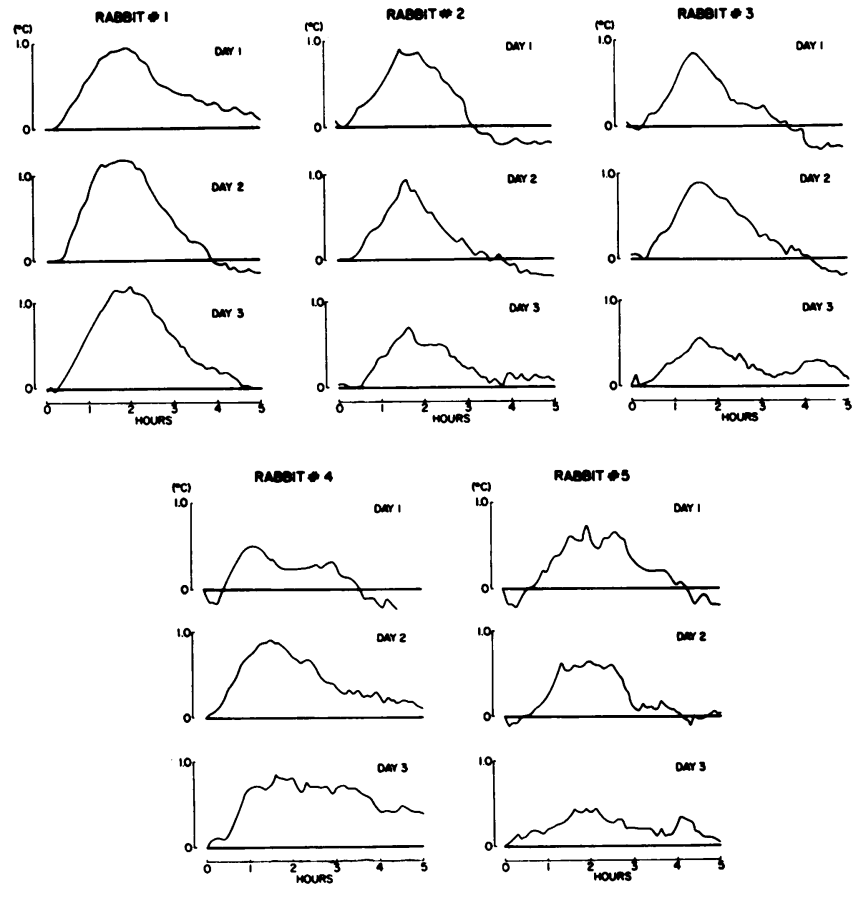

Figure 2. Individual rabbit responses to $5 \times 10^{6} \mathrm{U} / \mathrm{kg}$ hIFN injected by intravenous bolus. Each rabbit was injected with the same dose on each consecutive day.

shown in Fig. 2, there is a modest degree of pyrogenic tolerance in rabbits No. 2, 3, and 5. However, using a lower dose of IFN $\left(10^{6} \mathrm{U} / \mathrm{kg}\right)$, rabbits developed complete pyrogenic tolerance (Fig. 3).

Effect of hIFN on human MNC in vitro. To test for the ability of hIFN to stimulate human LP production, MNC from human donors were incubated with IFN in vitro and LP was measured in the supernatant medium. The concentrations of hIFN incubated with MNC were selected from the effective dose of pyrogenic agents in humans. For example, $E$. coli endotoxin produces fever in humans at $3 \mathrm{ng} / \mathrm{kg}(21,22)$ and $3 \mathrm{ng} / \mathrm{ml}$ of the same endotoxin is required to induce LP from human MNC in vitro. By analogy, MNC from 15 human donors were obtained and each was incubated with hIFN at

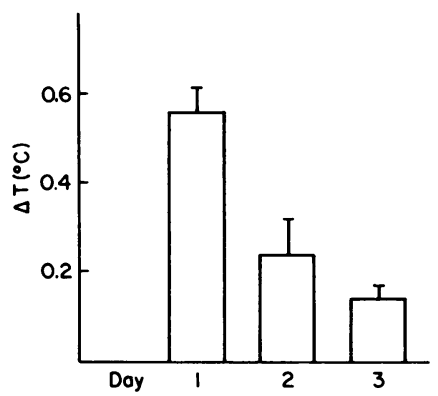

Figure 3. Mean peak fever $( \pm$ SEM) in five rabbits given daily injections of $10^{6} \mathrm{U} / \mathrm{kg}$. 
$10^{4}-10^{6} \mathrm{U} / \mathrm{ml}$ since most clinical studies have used between $10^{4}$ and $10^{5} \mathrm{U} / \mathrm{kg}$.

As shown in Fig. 4, MNC incubated with hIFN at a concentration of $10^{5} \mathrm{U} / \mathrm{ml}$ did not produce significant amounts of $\mathrm{LP}$, as measured in the rabbit assay $\left(10^{4} \mathrm{U} / \mathrm{ml}\right.$ also had no effect, data not shown); even $10^{6} \mathrm{U} / \mathrm{ml}$ did not induce LP production. In separate experiments, indomethacin $\left(10^{-6} \mathrm{M}\right)$, which has been shown to enhance LP production in vitro with other stimulators (23), was added to the incubation medium but had no effect. Only at concentrations of 2.5 and $5 \times 10^{6}$ $\mathrm{U} / \mathrm{ml}$ did the MNC supernatant contain significant, though still low, levels of LP. However, when MNC were incubated with hIFN in the presence of polymyxin B, a cationic antibiotic that blocks endotoxin-induced LP release $(24,25)$, LP production was reduced, suggesting that endotoxin contamination contributed to activation of human cells. From these studies, we conclude that recombinant hIFN may contain small amounts of endotoxinlike material that can be detected during incubation with human cells but that the concentrations of hIFN necessary to demonstrate the presence of such pyrogen have little, if any, clinical significance.

Effect of polymyxin $B$ on hIFN fever. The preceding experiments indicated that hIFN has no intrinsic ability to induce LP. Thus, we returned to the rabbit model to further study the mechanism of fever production by IFN. hIFN was tested again in the rabbit but the agent was first incubated with polymyxin $\mathrm{B}$ for 1-2 $\mathrm{h}$ before injection in the rabbit, to block any endotoxin contamination (24-26). Nevertheless, polymyxin B did not reduce hIFN fever in rabbits (Fig. 5 compared with Fig. 2). Also in Fig. 5, rabbits number 7, 8, and 10 develop a modest amount of pyrogenic tolerance to daily injections. Thus, it is unlikely that preparations of hIFN

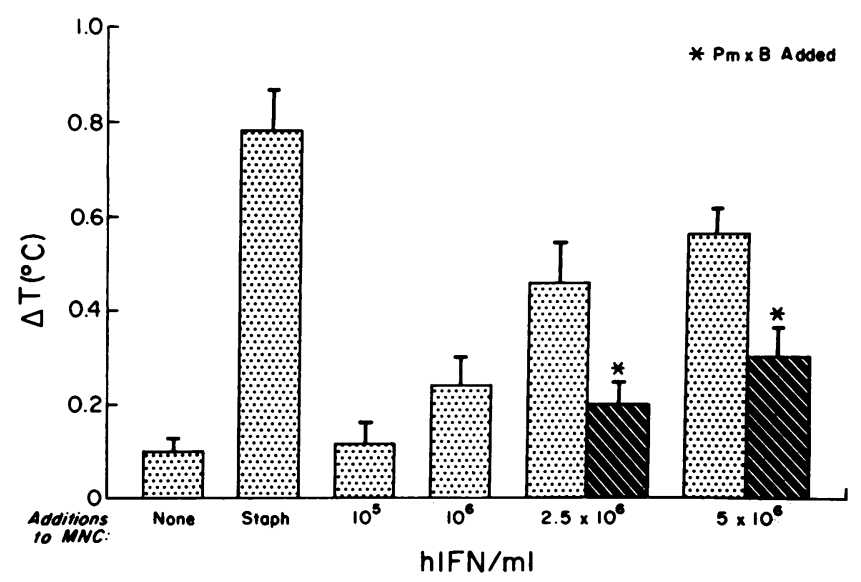

Figure 4. Mean peak fever $( \pm \mathrm{SEM})$ after intravenous injection of supernatants from human MNC incubated with materials indicated under the abscissa. Each supernatant was assayed by injection into three rabbits. MNC from 15 human subjects were individually studied. S. albus (indicated as Staph) was used as a positive control. Polymyxin B (PmxB) was added to MNC incubations at $12.5 \mu \mathrm{g} / \mathrm{ml}$.

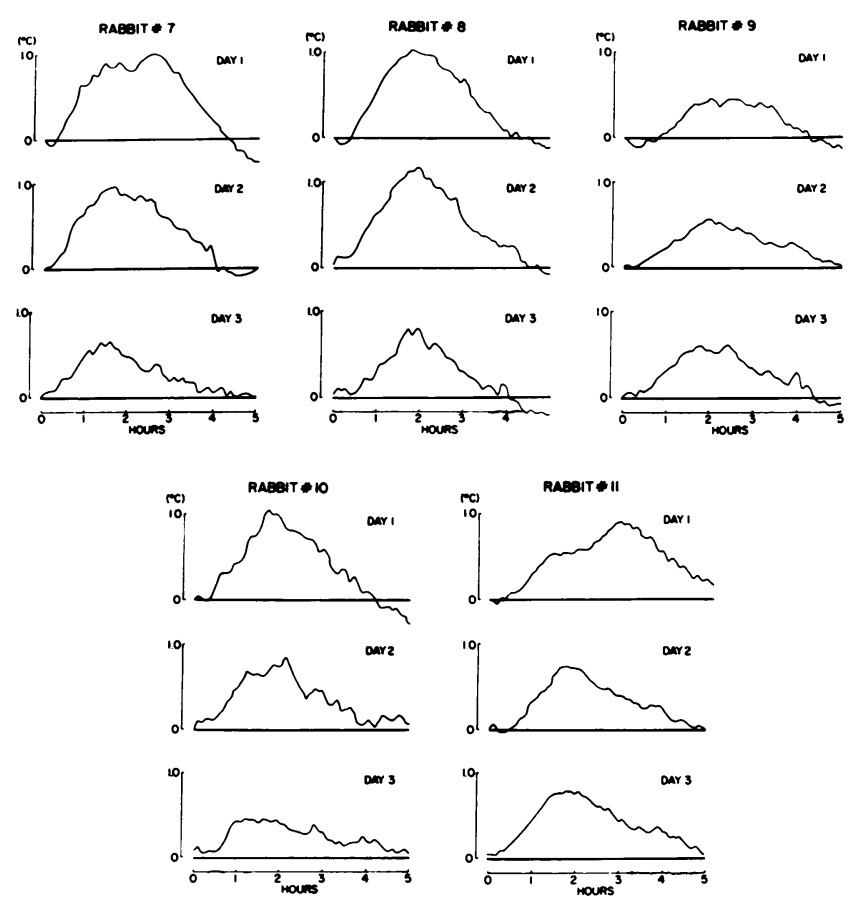

Figure 5. Individual rabbit responses to an intravenous bolus injection of $5 \times 10^{6} \mathrm{U} / \mathrm{kg}$ hIFN preincubated with polymyxin B $\left(37^{\circ} \mathrm{C}\right.$, $2 \mathrm{~h}$ ). hIFN was dissolved in pyrogen-free water and polymyxin B was added at a concentration of $100 \mu \mathrm{g} / 10^{6} \mathrm{U}$. Tests were repeated on each of three consecutive days.

are producing fever because they are contaminated with endotoxin.

hIFN fever in endotoxin-resistant mice. The murine febrile response to hIFN was similar to that observed in rabbits; it was dose dependent, of short latency and monophasic, but reached peak elevations at 25-30 min after injection (Fig. 6 $A$ ). This is similar to the fever produced after injection of LP in these mice (13). The minimal pyrogenic response was observed at $7.5 \times 10^{3} \mathrm{U}$ per mouse, while the optimal dose tested was $75 \times 10^{3} \mathrm{U}$ per mouse (Fig. $6 \mathrm{~B}$ ).

Absence of circulating LP during hIFN-induced fever in rabbits. Passive transfer of plasma from febrile rabbits was performed to demonstrate circulating LP (27). For these experiments, rabbits were injected with $1 \times 10^{7} \mathrm{U} / \mathrm{kg}$ intravenously; and at the time of peak fever (80-110 min postinjection) they were bled from the central ear artery into heparinized tubes. The plasma was then injected into another set of rabbits that had not previously received hIFN. Seven rabbits were injected with $10 \mathrm{ml}$ of febrile plasma and in another experiment five rabbits were injected with $20 \mathrm{ml}$ of plasma. In all passive transfer experiments, the presence of LP was not demonstrated (data not shown).

Stimulation of rabbit hypothalamic $P G E_{2}$ production by hIFN. Considerable evidence indicates that the synthesis of $\mathrm{PGE}_{2}$ in the preoptic anterior hypothalamic region is a primary 


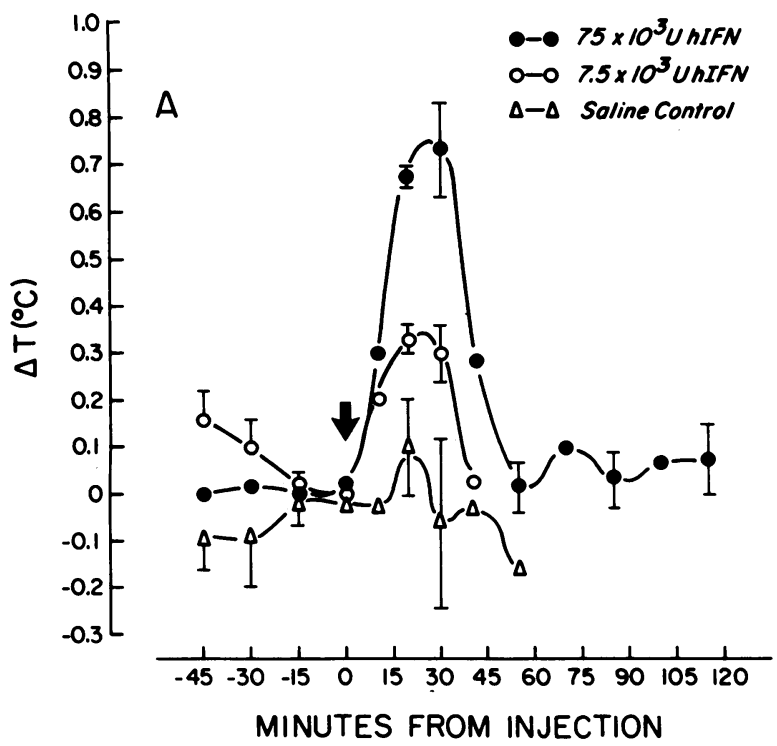

mechanism by which fever is initiated (28). Furthermore, LP given intrathecally, and to a lesser degree systemically, increases $\mathrm{PGE}_{2}$ levels in the CSF $(14,29)$. Experiments were carried out to ascertain whether hIFN by itself enhances hypothalamic $\mathrm{PGE}_{2}$ synthesis. We used an established model in which rabbit hypothalamic minces are incubated in vitro with agents that induce $\mathrm{PGE}_{2}$ synthesis (17). As shown in Fig. 7, incubation with MEM alone stimulated $\mathrm{PGE}_{2}$ production but this effect was prevented by polymyxin B. LAL testing of MEM revealed

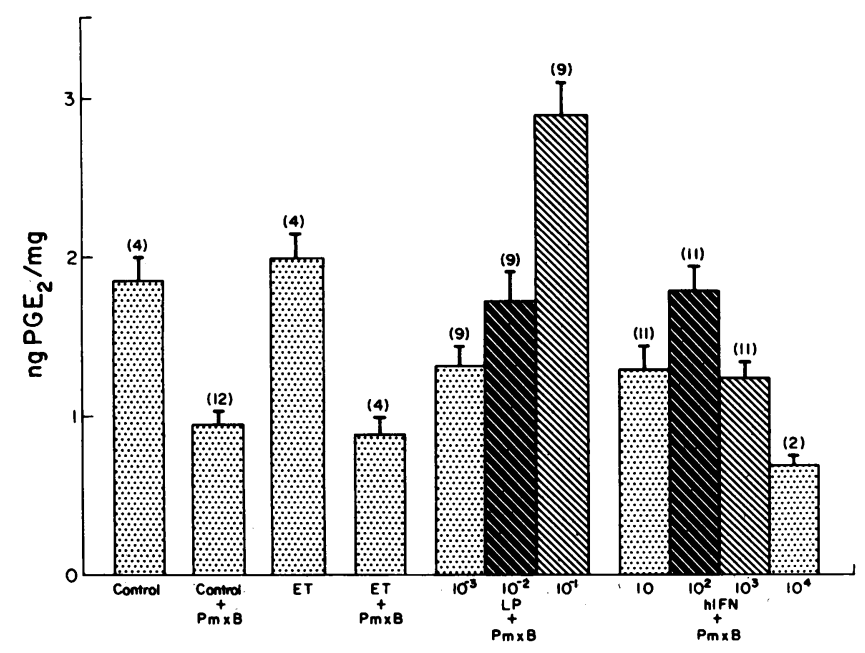

Figure 7. $\mathrm{PGE}_{2}$ production in rabbit hypothalamic tissue under conditions indicated below the abscissa. Number in parenthesis represents the total number of tissue incubations for each condition. Endotoxin (ET) concentration $=60 \mathrm{pg} / \mathrm{ml}$. Polymyxin B $(\mathrm{PmxB})$ concentration $=12.5 \mu \mathrm{g} / \mathrm{ml}$. LP concentrations are given as RPD per milliliter; hIFN concentrations are given as units per milliliter. Values are means \pm SEM.

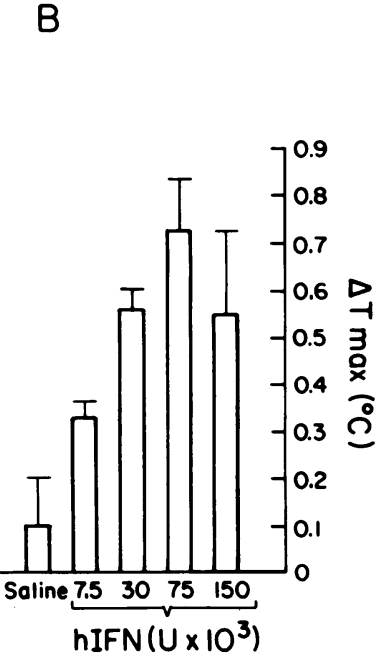

Figure 6. hIFN fever in $\mathrm{C} 3 \mathrm{H} / \mathrm{HeJ}$ mice. $(A)$ The mean $( \pm \mathrm{SEM})$ change in rectal temperature of mice injected intravenously with hIFN. $(B)$ The mean $( \pm$ SEM) maximal temperature increase in three to four mice injected with doses of hIFN as indicated. $\sim 25-50 \mathrm{pg} / \mathrm{ml}$. Since these results suggest that MEM stimulates hypothalamic tissue minces directly due to low levels of entotoxin, polymyxin B was added to all subsequent experiments shown in Fig. 7. As previously reported (17), highly purified preparations of human LP increased hypothalamic $\mathrm{PGE}_{2}$ production in the presence of polymyxin $\mathrm{B}$. Endotoxin added to hypothalamic incubations induced $\mathrm{PGE}_{2}$ release but this was blocked by polymyxin B. hIFN, on the other hand, induced $\mathrm{PGE}_{2}$ production beginning at $10 \mathrm{U} / \mathrm{ml}$, exerted maximal stimulation at $10^{2} \mathrm{U} / \mathrm{ml}$, and thereafter became less effective with increasing concentrations. A similar dose-response curve has been reported for IFN on natural killer cell activity (30). The results shown in Fig. 7 were also obtained when hIFN was used without the vehicle.

Effects of intracerebroventricular IFN in the cat. Injection of IFN $\left(0.5-2.5 \times 10^{6} \mathrm{U}\right.$ in 10-50 $\left.\mu \mathrm{l}\right)$ into the third ventricle of the conscious cat produced a biphasic response consisting of an initial hypothermia followed by hyperthermia. Hypothermia was immediate at onset, attained a nadir ( $T$, $-0.42 \pm 0.07^{\circ} \mathrm{C} ; 11$ cat injections) in $20-75$ min (mean, 39 $\mathrm{min}$ ), and continued for an additional 18-89 min (mean, 51 min). Thereafter, the temperature began to rise and a maximal elevation $(T, 1.61 \pm 0.2 ; 8$ exps.) was reached in 92-230 min (mean, $149 \mathrm{~min}$ ). Intraventricular injection of identical volumes of IFN vehicle (i.e., Elliott's solution with albumin and glycine) was followed by hypothermia $\left(T,-0.23 \pm 0.04^{\circ} \mathrm{C}\right)$ in six of eight experiments, while hyperthermia was never observed. When IFN was given intraventricularly in a larger volume $\left(1.25 \times 10^{6} \mathrm{U}\right.$ in $\left.125 \mu \mathrm{l}\right)$ no hypothermia ensued; however, hyperthermia $\left(T, 2.02 \pm 0.15^{\circ} \mathrm{C} ; 9\right.$ exps.) still occurred after a variable delay (mean, $75 \mathrm{~min}$; range, 29-133 $\mathrm{min}$ ) and its time course resembled that observed with more concentrated solutions of the compound. Furthermore, an equivalent volume of IFN vehicle had no effect. 
$\mathrm{PGE}_{2}$ was assayed in ventricular CSF and findings are summarized in Fig. 8. As shown, IFN stimulated the synthesis of $\mathrm{PGE}_{2}$ and its action was reflected in both a decrease in the number of samples with subthreshold activity and a rise in the measured levels of the compound. $\mathrm{PGE}_{2}$ elevation preceded the hyperthermia, both in the absence and the presence of a hypothermic component in the response to IFN. In contrast, the IFN vehicle either did not increase $\mathrm{PGE}_{2}$ above detection or it produced a marginal elevation. Indomethacin, given intraperitoneally at $2 \mathrm{mg} / \mathrm{kg}$, completely reversed the IFN fever and lowered $\mathrm{PGE}_{2}$ levels to unmeasurable values (2 exps.).

\section{Discussion}

The main conclusion from these studies is that IFN is an intrinsically pyrogenic substance whose action does not require the mediation of LP. Although the use of recombinant hIFN has resolved the question of IFN homogeneity, it has introduced the possibility of endotoxin contamination. Our results also indicate that endotoxin contamination does not account for the pyrogenicity of hIFN used in these studies. On a weight basis endotoxins are perhaps the most active pyrogens and produce fever in humans at doses of $1-3 \mathrm{ng} / \mathrm{kg}$ (31). Compared with rabbits, humans are highly sensitive to the pyrogenic property of endotoxins $(31,32)$. Therefore, one of the main objectives of our study was to rule out endotoxin contamination.

Clinical data using human cell-derived IFN have consistently demonstrated the development of pyrogenic tolerance to daily or frequent IFN therapy $(1-3,6,7)$. Tolerance to endotoxins is a well-documented phenomenon in both humans and rabbits $(12,19,20)$ and this occurrence certainly raises the question of endotoxin being involved in the genesis of IFN fever. However, tolerance is also observed with other pyrogenic stimuli such as daily administration of antigens in sensitized hosts (27). Although induction of antibody seems unlikely using human IFN in human subjects, there are indeed reports of antibodies to recombinant human insulin (33) and recombinant hIFN in recent clinical trials (9). In our study, there was a modest degree of tolerance to the high doses of hIFN; but with a smaller dose, rabbits developed pyrogenic tolerance within $3 \mathrm{~d}$. LP, on the other hand, produces the same fever in rabbits with daily injections even when rabbits are tolerant to endotoxins (34).

Additional data from our work suggest that recombinant hIFN causes fever independent of endotoxin contamination: (a) the fever response in rabbits to intravenous hIFN is consistently monophasic while endotoxin fever is often biphasic $(12,34) ;(b)$ the dose-response relationship of IFN is distinct from that of endotoxins; (c) polymyxin B effectively blocks
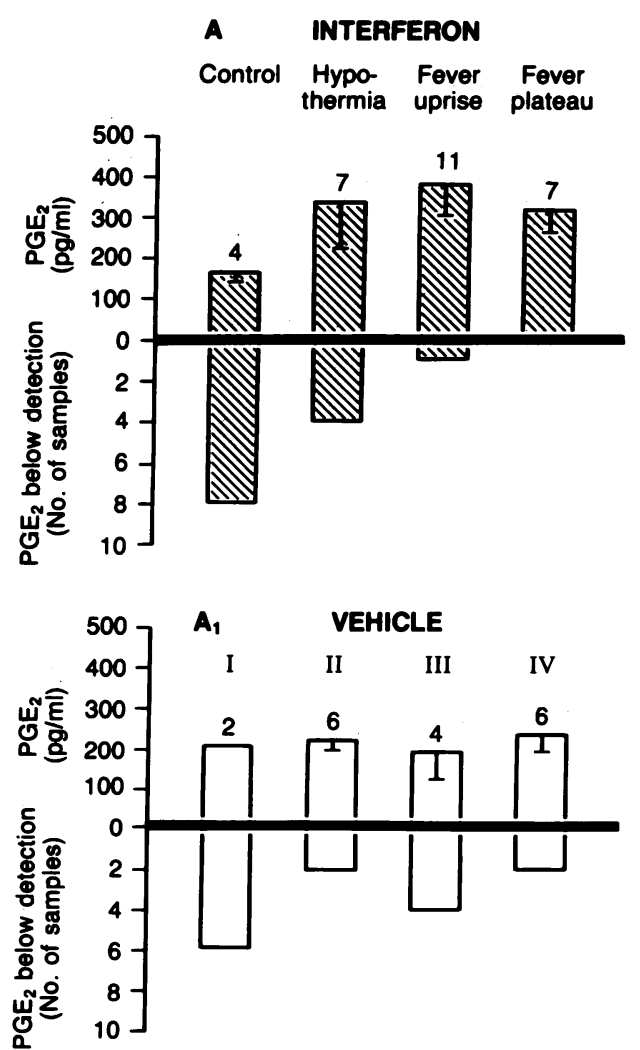

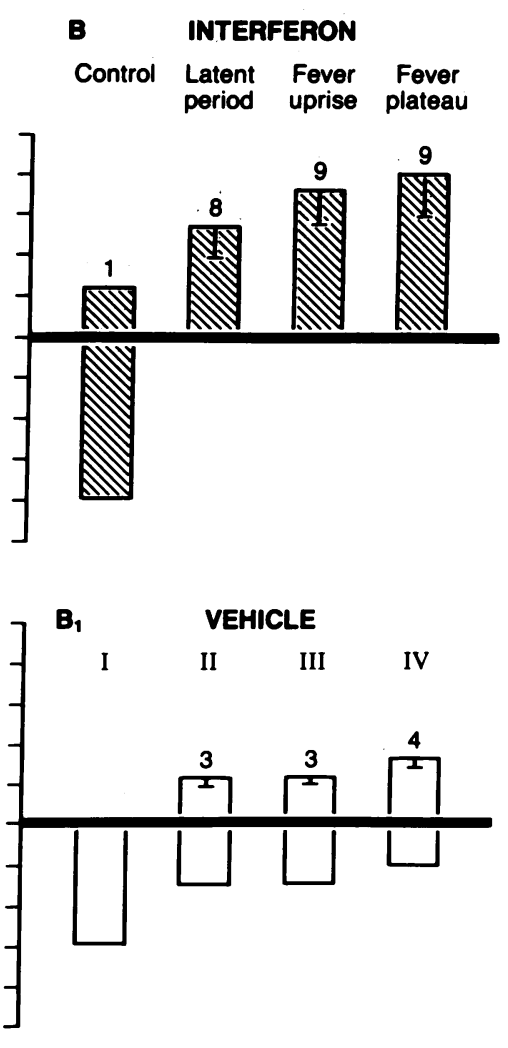

Figure 8. $\mathrm{PGE}_{2}$ concentration in CSF collected from the third ventricle under control conditions and during different phases of the response to intraventricular injection of hIFN (hatched bars). (A) IFN $0.5-2.5 \times 10^{6} \mathrm{U}$ in $10-50-\mu 1$ volumes. (B) IFN $1.25 \times 10^{6} \mathrm{U}$ in $125 \mu$ l volume. Findings with respective vehicle controls (open bars; see text for details) are given in $\left.A_{1}\right)$ and $\left(B_{1}\right)$. The latter samples were collected during normal temperature (I) and at intervals (II, III, IV) after vehicle injection corresponding chronologically to various stages of the response to IFN. $\mathrm{PGE}_{2}$ concentrations are means \pm SEM for the number of samples given above each column. Note that the threshold of the $\mathrm{PGE}_{2}$ assay differed between the two sets of experiments and was on the average $140 \mathrm{pg} / \mathrm{ml}$ (range 73-250/ml) and $88 \mathrm{pg} /$ $\mathrm{ml}$ (range $62-135 \mathrm{pg} / \mathrm{ml}$ ), respectively for panels $(A) /\left(A_{1}\right)$ and $(B) /\left(B_{1}\right)$. 
the fever of endotoxin while the antibiotic has no effect on hIFN fever; and (d) IFN fever was produced in the endotoxinresistant mouse strain $\mathrm{C} 3 \mathrm{H} / \mathrm{HeJ}$. This latter observation provides strong evidence against endotoxin being present in these preparations since these mice respond normally to LP but are genetically incapable of responding to all the biological effects of endotoxins (35). Finally, values of endotoxin contamination, as measured by the LAL test, do not correlate with the pyrogenicity of hIFN in both the rabbit and the cat. In fact, the threshold dose for intravenous (12) and intrathecal (36) endotoxin far exceeds any contamination in our IFN batch. Although we were able to stimulate human LP production with hIFN in vitro, the concentrations necessary to accomplish this were excessively high, i.e., $5 \times 10^{6} \mathrm{U} / \mathrm{ml}$ in the MNC cultures vs. $10^{4}-10^{5} \mathrm{U} / \mathrm{kg}$ in humans. Hence, doses of hIFN that produce fever in humans do not induce LP release from human MNC in vitro. On the basis of the measurable levels of endotoxin in these preparations $\left(7.5-12.5 \mathrm{ng} / 10^{8} \mathrm{U}\right)$, it is expected that $5 \times 10^{6} \mathrm{U} / \mathrm{ml}$ (containing $0.5 \mathrm{ng} / \mathrm{ml}$ endotoxin) should induce LP production (37).

Most fevers are mediated by LP $(34,38)$. Substances of host origin such as lymphokines induce LP production (39) and IFN could belong to this latter group. However, this possibility is not borne out by our findings since we were unable to show that human MNC produce LP when incubated with serum concentrations of hIFN measured during exogenous therapy (9). Recent studies have also shown that hIFN incubated with human MNC does not induce the production of interleukin-1 as assayed by lymphocyte activating factor (40). Although the implication from our studies is that IFN is by itself an endogenous pyrogen, we cannot rule out the possibility that IFN stimulates small quantities of LP from glial cells within the central nervous system (41).

The ability of hIFN to stimulate $\mathrm{PGE}_{2}$ production from rabbit hypothalamus in vitro supports the hypothesis that the agent, like LP, causes fever by raising the thermoregulatory set-point via a change in arachidonate cyclooxygenase products (28). LP induces a dose-related release of $\mathrm{PGE}_{2}$ from rabbit hypothalamic tissue (17); hIFN, on the other hand, while causing the release of $\mathrm{PGE}_{2}$ from rabbit brain tissue, differs from LP in its effectiveness over a narrow dose range. At 10 $\mathrm{U} / \mathrm{ml}$, hIFN increases $\mathrm{PGE}_{2}$ release over control values and a further increase is observed at $10^{2} \mathrm{U} / \mathrm{ml}$. However, as the dose of hIFN is raised beyond $10^{2} \mathrm{U} / \mathrm{ml}$ to $10^{3}-10^{4} \mathrm{U} / \mathrm{ml}$, the $P E_{2}$ output abates. The mechanism of this reduced production by higher concentrations of IFN is not clear.

Studies in cats confirm findings of hypothalamic incubations and provide information on the pyrogenicity of recombinant hIFN for intrathecal use. There are clinical data that demonstrate the rapidity of fever onset after intrathecal injection of human cell-derived IFN (42). Furthermore, one would expect this fever to be susceptible to antipyretic treatment. Thus, from the data presented in our studies it appears that IFN mimics LP in promoting $\mathrm{PGE}_{2}$ synthesis in the brain. This seems to be an intrinsic property of the IFN molecule, which does not express itself exclusively in nervous tissue since the agent also stimulates prostaglandin production in human fibroblasts (43). Finally, it is interesting to speculate on the similarities between mechanisms of action of LP and IFN. LP has recently been shown to increase skeletal muscle $\mathrm{PGE}_{2}$ synthesis and muscle protein breakdown in vitro (44). Thus, the myalgias and weight loss associated with fever from infectious noxae or IFN therapy $(8,9)$ may reflect actions on a common mechanism.

\section{Acknowledgments}

We thank Dr. Isis Bishai, Gail LoPreste, Dayle Huhtanen, Rohini Soni, and Edward Zaccharia for carrying out assays in these studies. The assistance of John Martens, Jodi Lees, Martin Brown, and Lorraine Barrie is gratefully acknowledged.

This work was supported by National Institutes of Health grants AI-15614, AI-17279, and AI-01564; Medical Research Council (Canada) grant MA-3310; and funds from Schering Corp.

\section{References}

1. Dunnick, J. K., and G. J. Galasso. 1979. Clinical trials with exogenous interferon: summary of a meeting. J. Infect. Dis. 139:109123.

2. Dunnick, J. K., and G. J. Galasso. 1980. Update on clinical trials with exogenous interferon. J. Infect. Dis. 142:293-299.

3. Ingimarsson, S., K. Cantell, and H. Strander. 1979. Side effects of long-term treatment with human leukocyte interferon. J. Infect. Dis. 140:560-563.

4. Bocci, V. 1980. Possible causes of fever after interferon administration. Biomedicine (Paris). 32:159-162.

5. Borg, H., E. Lundgren, M. D. Hollenberg, W. L. Veale, Y. H. Tan, and A. McPherson. 1981. Human interferon for clinical trials: removal of pyrogen by a simple two-step procedure. Can. J. Physiol. Pharmacol. 59:890-892.

6. Billiau, A. 1981. Pharmacokinetic and pharmacological aspects of interferon therapy in man. Acta Microbiol. Acad. Sci. Hung. 28:257262.

7. Billiau, A., J. H. Heine, J. van Damme, H. Heremans, and P. Somer. 1980. Tolerability of pure fibroblast interferon in man. Ann. NY Acad. Sci. 350:374-375.

8. Horning, S. J., J. D. Levine, R. A. Millar, S. A. Rosenberg, and T. C. Merigan. Clinical and immunologic effects of recombinant leukocyte A interferon in eight patients with advanced cancer. J. Am. Med. Assoc. 247:1718-1722.

9. Gutterman, J. U., S. Fine, J. Quesada, S. J. Horning, J. F. Levine, R. Alexanian, L. Bernhardt, M. Kramer, H. Spiegel, W. Colburn, P. Trown, T. C. Merigan, and Z. Dziewanowski. 1982. Recombinant leukocyte $\mathrm{A}$ interferon: pharmacokinetics, single-dose tolerance and biologic effects in cancer patients. Ann. Intern. Med. 96:549-556.

10. Dinarello, C. A., L. Renfer, and S. M. Wolff. 1977. Human leukocytic pyrogen: purification and development of a radioimmunoassay. Proc. Natl. Acad. Sci. USA. 74:4624-4627.

11. Dinarello, C. A. 1982. Endogenous Pyrogens. In Methods for studying mononuclear phagocytes. D. O. Adams, P. J. Edelson, and H. S. Koren, editors. Academic Press, Inc., New York. 629-639. 
12. Wolff, S. M., J. H. Mulholland, and S. B. Ward. 1965 Quantitative aspects of the pyrogenic response of rabbits to endotoxin. J. Lab. Clin. Med. 65:268-276.

13. Duff, G. W., and S. K. Durum. 1983. The pyrogenic and mitogenic actions of interleukin-1 are related. Nature (Lond.). 304:449451.

14. Coceani, F., I. Bishai, C. A. Dinarello, and F. A. Fitzpatrick 1983. Prostaglandin $E_{2}$ and thromboxane $B_{2}$ in cerebrospinal fluid of afebrile and febrile cat. Am. J. Physiol. 244:R785-R7932.

15. Dinarello, C. A. 1981. Demonstration of a human pyrogeninducing factor during mixed leukocyte reactions. J. Exp. Med. 153:1215-1224.

16. Dinarello, C. A., N. P. Goldin, and S. M. Wolff. 1974. Demonstration and characterization of two distinct human leukocytic pyrogens. J. Exp. Med. 139:1369-1381.

17. Dinarello, C. A., and H. A. Bernheim. 1981. Ability of human leukocytic pyrogen to stimulate brain prostaglandin synthesis in vitro. J. Neurochem. 37:702-708.

18. Dray, F., B. Charbonnel, and J. Maclouf. 1975. Radioimmunoassay of prostaglandins $F_{a l p h a}, E_{1}$ and $E_{2}$ in human plasma. Eur. $J$. Clin. Invest. 5:311-318.

19. Wolff, S. M., M. Rubenstein, J. H. Mulholland, and D. W. Alling. 1965. Comparison of hematologic and febrile response to endotoxin in man. Blood. 26:190-201.

20. Greisman, S. E., and R. B. Hornick. 1973. Mechanisms of endotoxin tolerance with special reference to man. J. Infect. Dis. 128:257-268.

21. Elin, R. J., L. Chedid, S. M. Wolff, K. P. W. J. McAdam, F. Audibert, C. Bernard, and F. Oberling. 1981. Properties of the reference endotoxin and its phthalylated derivative in humans. J. Infect. Dis. 144:329-338.

22. Dinarello, C. A., L. J. Rosenwasser, and S. M. Wolff. 1982. Demonstration of a circulating thymocyte suppressor factor during endotoxin fever in humans. J. Immunol. 127:2517-2519.

23. Parant, M., G. Riveau, F. Parant, C. A. Dinarello, S. M. Wolff, and L. Chedid. 1980. Effect of indomethacin on increased resistance to infection and on febrile responses induced by muramyldidpeptide. J. Infect. Dis. 142:708-714.

24. Duff, G. W., and E. Atkins. 1982. The inhibitory effect of polymyxin B on endotoxin-induced endogenous pyrogen production. $J$. Immunol. Methods. 52:333-340.

25. van Miert, A. S., and C. T. van Duin. 1978. Further studies on the antipyretic action of polymyxin B in pyrogen-induced fever. Arzneim. Forch. 28:2246-2251.

26. Rietschel, E. Th., U. Schade, M. Jensen, H.-W. Wollenweber, O. Luederitz, and S. G. Griesman. 1982. Bacterial endotoxins: chemical structure, biological activity and role in septicemia. Scand. J. Infect. Dis. Suppl. 31:8-21.

27. Atkins, E., and P. Bodel. 1974. Fever. In The Inflammatory Process. B. W. Zweibach, L. Grant, R. T. McCluskey, editors. Academic Press, Inc., New York. 467-514.
28. Milton, A. S. 1982. Prostaglandins in fever and the mode of antipyretic drugs. In Pyretics and Antipyretics. A. S. Milton, editor. Springer-Verlag, Berlin. 257-297.

29. Bernheim, H. A., T. M. Gelbiert, and J. T. Stitt. 1980. Prostaglandin E levels in the third ventricular cerebrospinal fluid of rabbits during fever and changes in body temperature. J. Physiol. (Lond.). 301:69-78.

30. Kohl, S. 1983. Stimulation of human natural killer cytotoxicity and protection of mice from infection due to Herpes Simplex by recombinant human leukocyte interferon. J. Infect. Dis. 147:484-488.

31. Wolff, S. M. 1973. Biological effects of bacterial endotoxins in man. J. Infect. Dis. 128(Suppl.):251-256.

32. Greisman, S. E., and R. B. Hornick. 1969. Comparative pyrogenic reactivity of rabbit and man to bacterial endotoxin. Proc. Soc. Exp. Biol. Med. 131:1154-1158.

33. Fireman, P., S. E. Fineberg, and J. A. Galloway. 1982. Development of IgE antibodies to human (recombinant DNA), porcine and bovine insulins in diabetic subjects. Diabetes Care. 5(Suppl.):119125.

34. Atkins, E. 1960. Pathogenesis of fever. Physiol. Rev. 40:580646.

35. Watson, J., M. Largen, and K. P. W. J. McAdam. 1978. Genetic control of endotoxic responses in mice. J. Exp. Med. 147:3947.

36. Dey, P. K., W. Feldberg, K. P. Gupta, and S. Wendlandt. 1975. Lipid A fever in cats. J. Physiol. (Lond.). 253:103-119.

37. Duff, G. W., and E. Atkins. 1982. The detection of endotoxin by in vitro production of endogenous pyrogen: comparison with the Limulus amebocyte lysate gelatin. J. Immunol. Meth. 13:323-331.

38. Dinarello, C. A., and S. M. Wolff. 1982. Molecular basis of fever. Am. J. Med. 72:799-819.

39. Bernheim, H. A., L. H. Block, and E. Atkins. 1979. Fever: pathogenesis, pathophysiology and purpose. Ann. Intern. Med. 91:261270.

40. Arenzana-Seisdedos, F., and J.-L. Virelizier. 1983. Interferons as macrophage-activating factors. II. Enhanced secretion of interleukin 1 by lipopolysaccharide-stimulated human monocytes. Eur. J. Immunol. 13:437-440.

41. Fontana, A., F. Kristensen, R. Dubs, D. Gemsa, and E. Weber. 1980. Production of prostaglandin $E$ and an interleukin-1 like factor by cultured astrocytes and C6 glioma cells. J. Immunol. 129:24132419.

42. Prange, $H$., and $H$. Wismann. 1981. Intrathecal use of interferon in encephalitis. N. Engl. J. Med. 305:1283-1284.

43. Fitzpatrick, F. A., and D. A. Stringfellow. 1980. Virus and interferon effects on cellular prostaglandin biosynthesis. J. Immunol. 125:431-437.

44. Baracos, V., H. P. Rodemann, C. A. Dinarello, and A. L. Goldberg. 1983. Stimulation of muscle protein degradation and prostaglandin $\mathrm{E}_{2}$ release by leukocytic pyrogen (interleukin-1). N. Engl. J. Med. 308:553-558. 